\title{
Surface Modification of Multi-walled Carbon Nanotubes for Enhancement of Dispersion and Electrochemical Properties
}

\author{
Young-Ja Kim, Wentao Zhang, Hong-Ro Lee*, Jong-Hyee Kim ${ }^{1}$ \\ Department of Applied Materials Engineering, Chungnam National University, Daejon 305-764, Korea \\ ${ }^{1}$ Div. of Future Fundamental Technology Research, Korea Institute of Energy Research, \\ Daejon 305-343, Korea
}

(Received October 2, 2008 ; revised October 20, 2008 ; accepted October 30, 2008)

\begin{abstract}
Several methods for improving dispersion of carbon nanotubes (CNTs) have been investigated. CNTs modified by acids and hydrogen peroxide $\left(\mathrm{H}_{2} \mathrm{O}_{2}\right)$ showed improved dispersion. From SEM micrographs and photos of dispersion, CNTs modified with nitric acid and $\mathrm{H}_{2} \mathrm{O}_{2}$, showed no agglomeration in solution even standing for 4 months, which means successfully improved dispersion property. TEM micrographs of surface modified single CNT treated with $69 \% \mathrm{HNO}_{3}$ in boiling acid solution as the optimum method were obtained. For confirmation of CNTs' application to EDLC electrode materials, characteristics of EDLC have been analyzed by cyclic voltammetry curve, specific capacitance of unit cell, electrode discharge curves and AC impedance curve. From the results, it could be confirmed that electrochemical properties of CNTs were enhanced after surface modification with $69 \% \mathrm{HNO}_{3}$ acid treatment.
\end{abstract}

Key words: Carbon nanotubes, Surface modification, Electrochemical properties, Electrode double layer

\section{Introduction}

Since early of 1990 s, the nanometric science and technology has been developed rapidly. As the most representative nanomaterials, carbon nanotubes (CNTs) are composed of graphite sheets rolled into closed concentric cylinders with diameter of the order of nanometers and length of micrometers. Since the discovery of CNTs in 1991 by Iijima ${ }^{1)}$, their extensive applications have been found in physical, chemical and material science fields, such as electronic nanodevices $^{2}$, catalyst carrier $^{3}$, electrochemical materials ${ }^{4}$, hydrogen storage materials ${ }^{5)}$ and composite reinforcement ${ }^{6}$. Until now, as CNTs have unique properties such as large specific surface area, high aspect ratio and good electrical conductivity, many studies have been focused on the application in super capacitors ${ }^{7-9)}$. The super capacitor which prepared with CNTs has several advantages of high power density, long life cycle, short charging time, and safety over the battery, so gave public attention for energy storage devices ${ }^{10}$.

*Corresponding author. E-mail : leehr@cnu.ac.kr
However, the raw CNTs usually contain a large amount of impurities, such as metal particles, amorphous carbon $^{11)}$. Such impurities are serious obstacle to characterize the properties of CNTs definitely. But more important obstacle is agglomeration of CNTs, which comes from CVD process as ropes or bundles to form a highly dense and complex network structure ${ }^{12}$. If agglomeration formed, it is difficult to disperse CNTs in organic or inorganic solvent, which is fatal to most actual applications. In most cases, CNT agglomerates do not provide three-dimensional networks which are needed efficiently to carry mechanical loads or provide useful transport properties for a mix or composite ${ }^{13)}$. There are several reports ${ }^{14-17)}$ on purification and surface modification of multiwalled CNTs (MWNTs) to obtain high specific surface area, such as cycloaddition and addition reaction with nitrene, acid, and diazonium salts, and so on. But still relationships between surface modification and electrochemical properties as an EDLC electrode material have been not defined clearly yet. For various applications of CNTs to super capacitor electrode materials, characteristics such as redox property, 
specific capacitance, discharging property and impedance property should be analyzed. In this paper we report surface modification method of MWNTs with $\mathrm{H}_{2} \mathrm{O}_{2}$, mixed acid $\left(\mathrm{H}_{2} \mathrm{SO}_{4}, \mathrm{HNO}_{3}\right), \mathrm{HNO}_{3}$, respectively for finding out optimum surface modification condition. Also, for examination of possibility of modified MWCNTs as EDLC electrodes materials, cyclic voltammetry curve of EDLC, specific capacitance of unit cell, self discharge voltage changes with open circuit and AC impedance measurement of modified CNTs were investigated before and after surface modification of MWCNTs, respectively.

\section{Experimental Procedure}

\subsection{Materials}

Raw MWNTs were prepared by using CVD method. Xylene was used as carbon source and $\mathrm{Fe}$ as catalyst. The reactive temperature was $800^{\circ} \mathrm{C}$. Aspect ratios of MWCNTs larger than 100 were used in this experiment. $69 \%$ nitric acid (G.R.), 98\% sulfuric acid (G.R.), and 30\% hydrogen peroxide (G.R.) were used. Other chemicals were of analytical grade and aqueous solutions were prepared with doubly-distilled water.

\subsection{Surface modification methods}

Raw CNTs were modified by different methods, separately. Detailed experimental procedures are as follows:

1) $\mathrm{H}_{2} \mathrm{O}_{2}$ treatment: In a $100 \mathrm{~mL}$ flask, $500 \mathrm{mg}$ raw CNTs and $30 \% \mathrm{H}_{2} \mathrm{O}_{2}$ are mixed, refluxing $36 \mathrm{~h}$, then by ultrasonic agitation. 0.5 hour, products were washed with distilled water to neutral, and then natural drying at room temperature in air.

2) Mixed acid treatment: $500 \mathrm{mg}$ raw CNTs was manually ground, suspended in $50 \mathrm{~mL}$ of a $3: 1(\mathrm{v} / \mathrm{v})$ mixture of concentrated $\mathrm{H}_{2} \mathrm{SO}_{4}(98 \%)$ and $\mathrm{HNO}_{3}$ $(69 \%)$ and refluxing the reaction system for 0.5 hour at $130 \sim 140^{\circ} \mathrm{C}$. After centrifugation, the upper colorless liquid was decanted and the resulting black solid was washed thoroughly with distilled water until the $\mathrm{pH}$ of the water was 7 .

3) $60 \% \mathrm{HNO}_{3}$ treatment: a total of $500 \mathrm{mg}$ raw CNTs was manually ground, suspended in $60 \%$ $\mathrm{HNO}_{3}$ and refluxed for 24 hours at $140^{\circ} \mathrm{C}$. After ultrasonication in a water bath for 6 hours, this was followed by several cycles of centrifugation/distilled water washing until the $\mathrm{pH}$ was around 7.

4) $69 \% \mathrm{HNO}_{3}$ treatment: sample $\left(69 \% \mathrm{HNO}_{3}\right.$ MWNTs) was obtained with an acid treatment of raw MWNTs. The treatment conditions was basically similar to that described for $60 \% \mathrm{HNO}_{3}$ treatment.

\subsection{Electrode preparation and work conditions}

1) 3 electrode half cell: Three-electrode system was introduced to test the performance as reported ${ }^{18)}$. $\mathrm{Pt}$ foil $\left(10 \times 10 \mathrm{~cm}^{2}, 100 \mu \mathrm{m} \mathrm{t}\right)$ was used as the counter electrode, saturated $\mathrm{Ag} / \mathrm{AgCl}$ served as the reference electrode, respectively, and $6 \mathrm{~mol} / \mathrm{L} \mathrm{KCl}$ solution as supporting electrolyte. The modified MWNTs immobilized with macromolecule bond dispersed on the surface of glassy carbon electrode, which used as the working electrode.

2) Unit cell: An EDLC unit cell was made up of the three-electrode system. $\mathrm{Ni}$ foam $\left(350 \mathrm{~g} / \mathrm{m}^{2}, 110\right.$ PPI, $900 \mu \mathrm{m} \mathrm{t}$ ) was used as a current collector, and 6 $\mathrm{mol} / \mathrm{L} \mathrm{KOH}$ solution was selected as supporting electrolyte. In the unit cell, the electrode size was required as $1 \times 1 \mathrm{~cm}^{2}$, and Scimat $(39 \mu \mathrm{m} \mathrm{t})$ was used as a separator of EDLC. The voltage was controlled at $0 \sim 0.9 \mathrm{~V}$ while unit cell was working.

\subsection{Characterization}

To observe the effect of modifiers and the dispersion of CNTs, SEM, A TMX 840 instrument, and TEM, JEOL2010 instrument at $200 \mathrm{kV}$ were utilized. Electrochemical behaviors of half cell and unit cell were examined on PARSTAT 2263 potentiostat.

\section{Results and Discussion}

SEM images of CNTs modified by different treatment were shown in Fig. 1. The raw materials
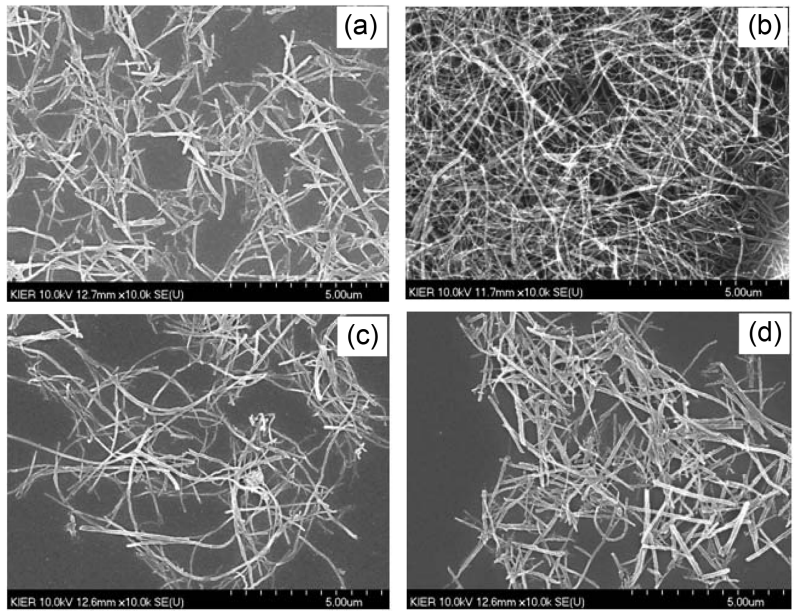

Fig. 1. SEM micrographs of modified CNTs with different treatment: (a) $\mathrm{H}_{2} \mathrm{O}_{2}$ refluxing $36 \mathrm{~h}$, ultrasonic 0.5 h, (b) Mixed acid $\left(\mathrm{H}_{2} \mathrm{SO}_{4}: \mathrm{HNO}_{3}=1: 3\right)$ refluxing 0.5 h, (c) $60 \% \mathrm{HNO}_{3}$ refluxing $24 \mathrm{~h}$, ultrasonic $7 \mathrm{~h}$ and (d) $69 \% \mathrm{HNO}_{3}$ refluxing $24 \mathrm{~h}$, ultrasonic $7 \mathrm{~h}$. 


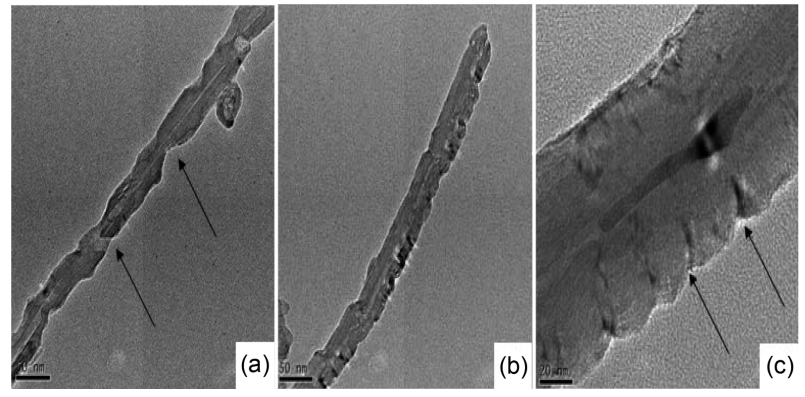

Fig. 2. TEM micrographs of single CNT modified by (a) $\mathrm{H}_{2} \mathrm{O}_{2}$ refluxing $36 \mathrm{~h}$, (b) $69 \% \mathrm{HNO}_{3} 36 \mathrm{~h}$, ultrasonic cleaning for $7 \mathrm{hr}$ and (c) magnified Fig. (b).

from the synthesis process by CVD were shown mainly in the form of large irregular agglomerates, which contains numerous CNTs. After $\mathrm{H}_{2} \mathrm{O}_{2}$ and acid treatments, the impurities were removed successfully, and dispersions of modified CNTs were improved Fig. 1(a). The length of CNTs was cut into several segments uniformly, the specific surface area of CNTs was increased successfully especially at $\mathrm{H}_{2} \mathrm{O}_{2}$ refluxing $36 \mathrm{~h}$ (a) and $69 \% \mathrm{HNO}_{3}$ refluxing $24 \mathrm{~h}(\mathrm{~d})$ treatment. From SEM results, the expected purpose was obtained by $\mathrm{H}_{2} \mathrm{O}_{2}$ and $69 \% \mathrm{HNO}_{3}$ treatment.

In order to go further to investigate the microscopic effect of $\mathrm{H}_{2} \mathrm{O}_{2}$ and $69 \% \mathrm{HNO}_{3}$ treatment on CNTs, TEM photographs of modified CNTs were observed as Fig. 2. After modified with $\mathrm{H}_{2} \mathrm{O}_{2}$ and $69 \% \mathrm{HNO}_{3}$, the surface defects of CNTs increased significantly, which lead to break down during ultrasonic agitation and finally increase specific surface area. But after modified by $\mathrm{H}_{2} \mathrm{O}_{2}$ treatment (Fig. 2(a)), the surface defects were introduced seriously, and the obtained weight loss of CNTs was so large that the structure of CNTs was damaged severely. Using $69 \% \mathrm{HNO}_{3}$ to modify CNTs, many defects were obtained on the surface of CNTs, but weight loss was not serious. From Fig. 2(b) and (c) the defects which obtained at this condition were narrow and deep, and this lead to the conductivity decrease of CNTs. From the results of SEM and TEM observation, $69 \% \mathrm{HNO}_{3}$ treatment was optimum method for modifying CNTs.

Fig. 3 showed dispersion property of raw CNTs (a) and $69 \% \mathrm{HNO}_{3}$ modified CNTs keeping 4 months in water (b). Before acid treatment, the row CNTs existed as ropes or bundles to form a highly dense and complex network structure, which made them entangled each other or agglomerated in solution, so it is difficult to disperse CNTs in organic or inorganic solvent. After with $\mathrm{HNO}_{3}$ modification, the dispersion of CNTs was improved obviously, and the modified CNTs could be dispersed in the water uniformly and

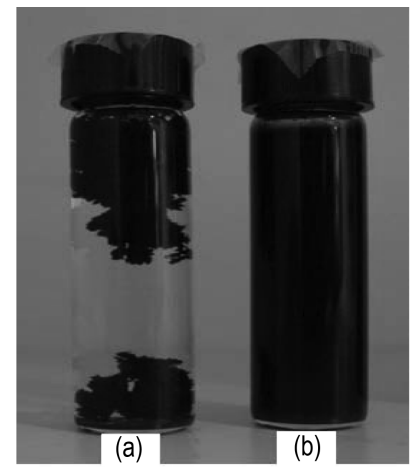

Fig. 3. Dispersion property photo of untreated CNTs (a) and $69 \% \mathrm{HNO}_{3}$ modified CNTs (b) keep 4 months in water after ultrasonic cleaning for 10 mins.

stably, even 4 months later. Without entangle of nanotubes with each other or agglomeration in solution, they might be expected to form a uniform suspended phase. This may be achieved by decreasing the length of the nanotubes by surface modification to reduce physical entanglement. $\mathrm{HNO}_{3}$ seems to decrease Van der Waals action and conjugation effect between $\mathrm{CNTs}$, which prevent the agglomeration of $\mathrm{CNTs}^{19}$.

According to the energy storage theory of carbonbased capacitor, the cyclic voltammogram curves of ideal super capacitors should be shown standard rectangular symmetric curves. In the actual system, due to the existence of electrode polarization resistance, the cyclic voltammogram curves of carbon-based capacitors often have a certain deviation ${ }^{20)}$. Fig. 4 showed that cyclic voltammogram curves of $\mathrm{Ag} /$ $\mathrm{AgCl}$ electrode in inorganic electrolytic system which from -1 to $0 \mathrm{mV}$. It was seen that, the capacity of treated CNTs was more than twice of untreated $\mathrm{CNTs}$, and the cyclic voltammogram curves were symmetric commendably. From Fig. 4(a), it was observed that any electrochemical reaction did not occurred, and CNTs could exist stably on the surface of electrode. But a couple of well-defined and nearly

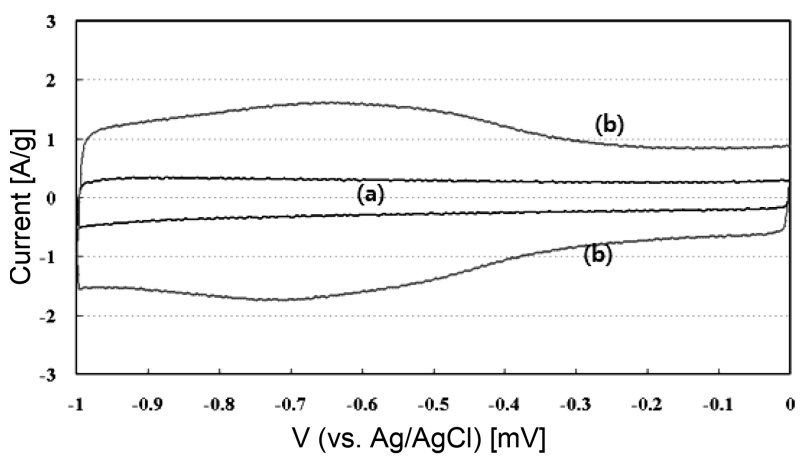

Fig. 4. Cyclic voltammogram curves of $\mathrm{Ag} / \mathrm{AgCl}$ electrode with (a) raw MWNTS and (b) $\mathrm{HNO}_{3}$ modified MWNTs. 


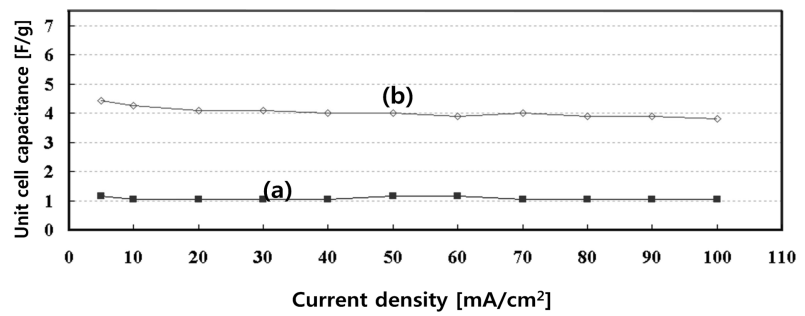

Fig. 5. Specific Capacitance of untreated CNTs-base (a) and treated CNTs-base (b) unit cell with different current density.

symmetrical redox peaks were appeared in Fig. 4(b), The cyclic voltammogram results indicate that redox peaks were attained by the direct electron transfer reaction of electrode, and which was caused by promotion of modified CNTs. After CNTs were modified by $\mathrm{HNO}_{3}$, many oxygen-contained functional groups, such as $-\mathrm{COOH},-\mathrm{OH}$ and $>\mathrm{C}=\mathrm{O}$, were grafting onto the surface of CNTs, and these groups seems to play promoting role successfully for the electron transfer reaction ${ }^{21)}$.

Fig. 5 showed that unit cell capacitance curves of CNTs-based capacitor with different current density from 5 to $100 \mathrm{~mA} / \mathrm{cm}^{2}$. Higher specific capacitance of about $4 \sim 5 \mathrm{~F} / \mathrm{g}$ was obtained at various current density and with chemical treatment. It seems to be the reason through the attachment of a variety of surface function groups formed during thermal, chemical or electrochemical treatments on surfaces ${ }^{22,23)}$. From the results, the specific capacitance of EDLC of surface treated CNTs was much higher than that of untreated CNTs capacitor. They kept stable specific capacitance value with current increasing from 5 to $100 \mathrm{~mA} / \mathrm{cm}^{2}$. From Fig. 5b), it could be seen that the modified CNTs capacitor still had $4 \mathrm{~F} / \mathrm{g}$ special capacitance in wide current ranges, which showed extremely stable capacity.

Electrochemical impedance spectroscopy (EIS) is a highly effective tool for probing the features of surface-modified electrodes. To get better insight into the resistance contributions, Alternating current (AC) impedance measurement of both capacitors were performed. Fig. 6 shows the results of EIS, presented as Nyquist plots, for the raw CNTs electrode and modified CNTs electrode, which were collected in the frequency range of $1 \mathrm{MHz} 16.5 \mathrm{kHz}$ with the amplitude of $10 \mathrm{mV}$. EIS showed that one contain arc at high frequency area, and there has a bias line at low frequency area, which corresponded to diffusion impedance. This observation could be interpreted in terms of existence of the resistance to charge transfer originating from faradic reactions occurring at elec-

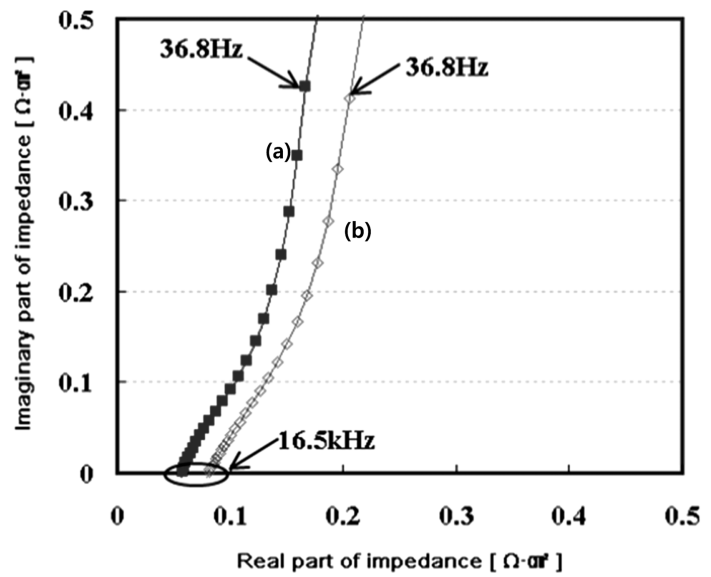

Fig. 6. Nyquist impedance plots of raw CNTs electrode (a) and modified CNTs electrode (b).

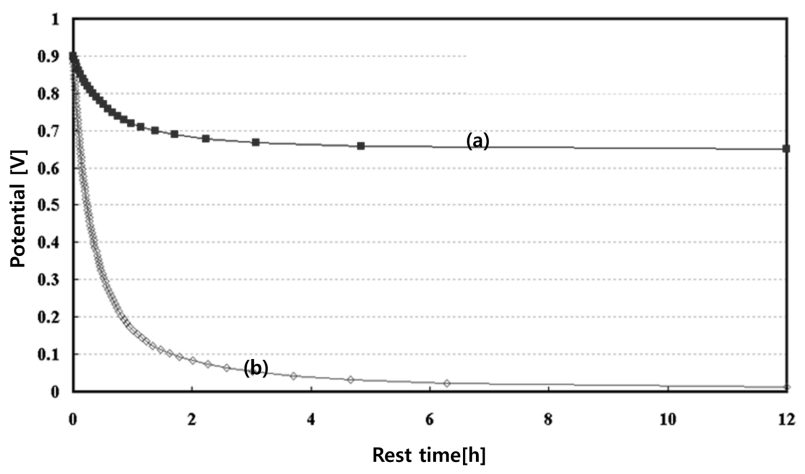

Fig. 7. Self discharge voltage changes of raw MWNTs (a) and modified MWNTs (b) with open circuit.

trodes and from the porous structure of the active material. Regardless some uncertainty of the applied equivalent circuit, impedance measurements permitted to determine charge-transfer resistances ${ }^{24)}$. After modified with $\mathrm{HNO}_{3}$, many metal particles, and carbon atoms were removed, and large numbers of carboxyl increased on the carbon tubes wall, which decreased the surface activity of CNTs, so the contact resistance of modified CNTs was increased. From Fig. 6, real impedance of modified CNTs electrode was higher than that of xylene CNTs.

Results about self discharging of raw CNTs electrode and modified CNTs electrode were shown in Fig. 7. Self discharging curves indicates that discharging rate of modified CNTs electrode is higher than that of xylene CNTs. Fig. 7 shows rapid degradation at the first stage which seems to be the reason from rapid oxygen evolution on electrode. Acid sites such as $-\mathrm{COOH},-\mathrm{OH}$, and $>\mathrm{C}=\mathrm{O}$ attached to electrode surface will increase the oxidation rate which will result in self discharging rate to increase rapidly. So it could be confirmed that $\mathrm{HNO}_{3}$ and ultrasonic treatment is good for dispersion induction and 
capacitance increment, but it is not good for resistance and self discharging property.

\section{Conclusions}

$\mathrm{H}_{2} \mathrm{O}_{2}$ which is usually used by mixing with $\mathrm{H}_{2} \mathrm{SO}_{4}$ and $\mathrm{HNO}_{3}$ is most effective to cut down length of CNTs shortly among chemicals. But $\mathrm{H}_{2} \mathrm{O}_{2}$ treatment has too large amount of weight loss due to so low yield ratio. So, in this experiment only $69 \% \mathrm{HNO}_{3}$ treatment is selected for surface modification for CNTs surface modification. It made sharp and deep defects like notch or crack, which is effective for cutting CNTs during ultrasonic vibration. CNTs modified by $69 \% \mathrm{HNO}_{3}$ for EDLC electrode showed many advantages, especially good dispersion property and high specific surface area. From CV measurement of unit cell, capacitance of EDL is increased. Also, specific capacitance was increased after surface modification treatment. As a conclusion, $\mathrm{HNO}_{3}$ and ultrasonic vibrating treatment is good for enhancing dispersion property and increasing capacitance, but it is rather not good owing to increasing resistance of CNTs by notch formation on surface and increasing self discharging rapidly by acid sites formation on electrode which will increase oxidation rate.

\section{References}

1. S. Iijima, Nature, 354 (1991) 56.

2. T. W. Ebbessen, Ann. Rev. Mater. Sci. 24 (1994) 235.

3. Christopher A, Dyke, M. James. Phys. Chem. A, 10 (2004) 11.

4. C. Dekker, Physics Today, 52 (1999) 22.

5. V. Skakalova, U. Dettlaff-Weglikowska, S. Roth, Diamond and Related Materials, 13 (2004) 296.

6. H. W. C. Postma, T. Teepen, Z. Yao, M. Grifoni,
C. Dekker, Science, 293 (2001) 76.

7. C. Niu, E. K. Sichel, R. Hoch, D. Moy, H. Tennent, Appl. Phys. Lett., 70 (1997) 1480.

8. R. Z. Ma, J. Liang, B. Q. Wei, B. Zhang, C. L. $\mathrm{Xu}$, J. Power Sources, 84 (1999) 126.

9. S. Wei, W. P. Kang, J. L. Davidson, J. H. Huang, Diam. Relat. Mater., 17 (2008) 906.

10. J. Y. Lee, K. Liang, K. H. An, Y. H. Lee, Synthet. Met., 150 (2005) 153.

11. P. X. Hou, S. Bai, Q. H. Yang, C. Liu, H. M. Cheng, Carbon, 40 (2002) 81.

12. J. Li, T. Tang, X. Zhang, S. Li, M. Li, Mater. Lett., 61 (2007) 4351.

13. N. Pierard, A. Fonseca, I. Willems, G. Van Tendeloo, J. B.Nagy, Chem. Phys. Lett. 335 (2001) 1.

14. P. M. Ajayan, T. W. Ebbesen, T. Ichihashi, S. Iijima, K. Tanigaki, Nature, 362 (1993) 522.

15. Y. P. Sun, K. Fu, Y. Lin, W. Huang, Accounts Chem. Res. 35 (2002) 1096.

16. S. Niyogl, M. A. Hamon, H. Hu, B. Zhao, P. Bhowmik, R. Sen, M. E. Itkis, R. C. Haddon, Accounts Chem. Res. 35 (2002) 1105.

17. D. M. Guldi, G. M. A. Rahman, V. Sgobba, C. Ehli, Chem. Soc. Rev. 35 (2006) 471.

18. M. Yang, J. Jiang, Y. Yang, X. Chen, G. Shen, Biosens. and Bioelectron. 21 (2006) 1791.

19. J. L. Lyon, K. J. Stevenson, Electrochim. Acta, 53 (2008) 6714.

20. G. Wang, M. Qu, Z. Yu, R. Yuan, Mater. Chem. Phys. 105 (2007) 169.

21. L. Li, G. Wu, B. Q. Xu, Carbon, 44 (2006) 2973.

22. S. M. Lipka, IEEE AES Systems Magazine, July 1997.

23. T. Momma, X. Liu, T. Osaka, Y. Ushio, Y. Sawada, J. Power Sources, 60 (1996) 249.

24. F. Pico, C. Pecharroman, A. Anson, M. T. Martinez, J. M. Rojo, J. Electrochem. Soc. 154 (2007) A579. 